\title{
Intracranial Aneurysms: A Clinical, Angiographic and Computerized Tomographic Study
}

\author{
BRYCE WEIR, JACK MILLER, AND DON RUSSELL
}

SUMMARY. Fifty-six patients with 63 aneurvims were selected from a larger group of patients because they had at least one angiographic and one CT scan studv. A total of 102 CT scans and 136 angiograms were analyzed. In five patients the aneurysm was visualized on the CT scan. There was a tendency for the location of the subarachnoid hemorrhage and intracerebral hematomas visualized on the CT scans to correlate with the site of the aneurysm as seen on the angiogram. The CT scan was useful in demonstrating the evolution of hydrocephalus and in differentiating hematoma from edema. The patients with normal CT scans were more likely to have good neurological grades. No single angiographic or CT scan feature correlated significantly with survival at lower than the 5 percent level.

RÉSUMÉ: Cinquante-six patients avec 63 anérrismes furent sélectionnés parmi un plus grand nombre de patients ayant eu au moins une étude angiographique et un CT scan. Un total de 102 CT scans et de 1.36 angiogrammes furent analysés. Chez cing patients, l'anévrisme fut visualisé au CT scan. La localisation des hémorragies méningées et des hématomés intracérébraux visualisés aux CT scans correspondait au site de l'anérrisme tel que v'u à l'angiogramme. Le CT scan est d'une grande utlité pour démontrer l'évolution de l'hydrocéphalie et pour différencier l'hématome de l'édoeme dans les lésions expansives. Les patients avec $C T$ scans normaux étaient plus susceptibles d'être classés comme neurologiquement presque normaux. Aucune des données angiographique ou du CT scan ne correspondait significativement à la survie des patients.

From the Division of Neurosurgery and Department of Radiology. Faculty of Medicine, University of Alberta, Edmonton.

Reprint requests to Dr. B.K.A. Weir, 5208409 112 St. Edmonton, Alberta T6G 1K6, Canada.

\section{INTRODUCTION}

The advent of CT scanning has had a dramatic effect on virtually every field in clinical neurosurgery. Intracranial aneurysms do not appear to be an exception.

\section{METHOD}

We have analyzed 56 patients who had a total of 63 intracranial aneurysms. They were selected from a larger group of aneurysm patients because they all had at least one angiographic and one CT scan study. A total of $102 \mathrm{CT}$ scans and 136 angiograms were analyzed.

\section{RESULTS}

Of the 56 patients, 51 had a history of subarachnoid hemorrhage. In 5, the aneurysms were assumed to have been unruptured. Fifty-four patients were operated on, of whom 14 (26\%) died. The 2 patients not operated on died. Of those operated, 28 had clipping of the aneurysm, 9 had clipping of the aneurysm and a CSF shunting procedure, 6 had a shunt only, 4 had inspection and wrapping of the aneurysm and 7 had carotid ligation.

The sites of the aneurysms were: internal carotid, $19(30 \%)$; middle cerebral, 19 (30\%); anterior cerebral, 19 (30\%); and vertebral/basilar, 6 (11\%). Six (11\%) of the patients had multiple aneurysms. In 5 of the patients the aneurysm was visualized on the CT scan (Figures 1a, 1b).

In one patient, case 15 , the aneurysm was seen to be larger on the CT scan than on the angiogram. In another patient, case 56, the aneurysm was seen on CT scan only because there was no filling on the angiogram due to raised intracranial pressure.

Table 1 demonstrates the location of subarachnoid hemorrhage and intracerebral hematomas visualized on CT scan, correlated with the site of the aneurysm seen on the angiogram. Examples of subarachnoid hemorrhage are shown in Figure 2, intracerebral hematomas, Figure 3 and intraventricular hemorrhages in Figure 4. A comparison of the evidence for a mass lesion on angiogram and on CT scan, where such studies were performed within two days of each other, is given in Table 2 . Figure 5 demonstrates the principal changes seen with a space occupying lesion resulting from an aneurysm. The aneurysm itself is a large left middle fossa mass, a hemorrhage is seen superior to the aneurysm and there is a halo of edema. This has resulted in a ventricular midline shift and dilatation of the posterior portion of the ventricular system. On this patient there was no intracranial filling on the angiogram.

An analysis of the $\mathrm{CT}$ findings with respect to the presence of spasm on the pre-operative or postoperative angiograms is given in Table 3.

The width of the ventricles immediately behind the frontal horns between the two caudate nuclei at the point where the walls were approximately parallel was measured with a millimeter rule and compared to the width of the brain at the same level. This ventriculocranial ratio and its variation with time is shown in Table 4. The evolution of hydrocephalus in an individual patient is shown in Figure 6. Comparison of CT scans in the first week following subarachnoid hemorrhage and sub- 
TABLE 1

Location of $S A H$ and ICH by Aneurysm Site

\begin{tabular}{|c|c|c|c|c|c|c|c|c|c|c|c|c|c|c|c|c|c|c|c|c|c|c|c|c|c|c|c|c|c|c|c|}
\hline & & \multicolumn{3}{|c|}{$\mathbf{F r}$} & \multicolumn{3}{|c|}{ PeBa } & \multicolumn{3}{|c|}{ Cal } & \multicolumn{3}{|c|}{ PaSy } & \multicolumn{3}{|c|}{ Par } & \multicolumn{3}{|c|}{ Te } & \multicolumn{3}{|c|}{ Cau } & \multicolumn{3}{|c|}{ Th } & \multicolumn{3}{|c|}{ Oc } & \multicolumn{3}{|c|}{ Cap } \\
\hline SITE & $\begin{array}{l}\text { NO. CT } \\
\text { SCANS }\end{array}$ & $\mathrm{n}$ & $\mathbf{R} \%$ & $\mathrm{C} \%$ & $\mathbf{n}$ & R\% & C\% & $\mathrm{n}$ & R\% & $\mathrm{C} \%$ & $\mathbf{n}$ & R\% & C\% & $\mathrm{n}$ & $\mathrm{R} \%$ & $\mathrm{C} \%$ & n & R\% & $\mathrm{C} \%$ & $\mathrm{n}$ & $\mathrm{R} \%$ & C $\%$ & $\mathrm{n}$ & $\mathrm{R} \%$ & C\% & $\mathrm{n}$ & $\mathrm{R} \%$ & C\% & $\mathbf{n}$ & $\mathrm{R} \%$ & $\mathrm{C} \%$ \\
\hline $\mathrm{AC}$ & 43 & 15 & 35 & 79 & 3 & 7 & 30 & 7 & 16 & 78 & 1 & 2 & 11 & 0 & 0 & 0 & 0 & 0 & 0 & 2 & 5 & 40 & 0 & 0 & 0 & 1 & 2 & 100 & 0 & 0 & 0 \\
\hline $\mathrm{MC}$ & 35 & 2 & 6 & 11 & 0 & 0 & 0 & 0 & 0 & 0 & 5 & 14 & 56 & 4 & 11 & 44 & 3 & 9 & 60 & 1 & 3 & 20 & 1 & 3 & 100 & 0 & 0 & 0 & 0 & 0 & 0 \\
\hline IC & 48 & 2 & 4 & 11 & 4 & 8 & 40 & 2 & 4 & 22 & 2 & 4 & 22 & 5 & 10 & 56 & 2 & 4 & 40 & 2 & 4 & 40 & 0 & 0 & 0 & 0 & 0 & 0 & 1 & 2 & 100 \\
\hline VB & 16 & 0 & 0 & 0 & 3 & 19 & 30 & 0 & 0 & 0 & 1 & 6 & 11 & 0 & 0 & 0 & 0 & 0 & 0 & 0 & 0 & 0 & 0 & 0 & 0 & 0 & 0 & 0 & 0 & 0 & 0 \\
\hline
\end{tabular}

SAH - subarachnoid hemorrhage, ICH - intracerebral hematoma, AC - anterior cerebral,

MC - middle cerebral, IC - internal carotid, VB - vertebral basilar, Fr - frontal lobe,

$\mathrm{PeBa}$ - peribasal, Cal - callosal, PaSy - para-sylvian, Par - parietal lobe,

$\mathrm{Te}$ - temporal lobe, Cau - caudate nucleus, Th - thalamus, Oc - occipital lobe,

Cap - internal capsule, R\% - row percent, C\% - column percent, $\mathrm{n}-$ number $\mathrm{CT}$ scans.

sequently, showed an increase in ventricular size in $10(77 \%)$ of these cases. In $3(23 \%)$ there appeared to be a decrease in ventricular size on the second scan. The average interval between the two scans was 25 days for both groups. Of the 10 patients who were treated by ventricular shunting, 9 showed a postoperative decrease in ventricular size and one showed an increase. The effect of shunting on ventricular size is illustrated in Figure 7.

Table 5 correlates the pathology shown on the CT scan with the neurologic grade of the patient at the time of the scan.

The development of infarction following aneurysm rupture and operation can be followed by serial CT scans. With a mature infarct the adjacent ventricular system is generally dilated and may be shifted towards the lesion (Figure 8), whereas in edema the opposite is true. In both instances the CT scan demonstrates an area of lucency in the affected area.

Relatively normal CT scans are common following subarachnoid hemorrhage. These patients are more likely to have good neurological grades. Their outlook, however, is not necessarily better than patients who have obvious hematomas.

Table 6 gives the clinical outcome with respect to the $\mathrm{CT}$ scan and angiographic findings. A test of proportions showed that none of the factors measured on angiograms or CT scans correlated significantly with survival at lower than the 5 percent level. The presence of intraventricular hemorrhage preoperatively was closest $(p<.1$, significant at 10 percent level). The average clinical grade for the patients who died was 3 and for those which survived was 2 .

It is sometimes difficult to obtain satisfactory CT scans on patients post-operatively because of artefact produced by the patient's inability to cooperate fully. In the pre-operative CT scans 20 percent showed significant artefact, in the postoperative CT scan 59 percent showed artefact and in 77 percent the aneurysm clip, or its effect, was demonstrated.

\section{DISCUSSION}

Our findings are comparable to those of Kendall et al. (1976). In their series of 43 aneurysms they retrospectively correctly localized the site of the ruptured aneurysm in 31 cases. In 12, the CT scan did not permit a localization. They noted that localization was more likely in the seven days immediately following subarachnoid hemorrhage $(86 \%$ localized) rather than later (34\%). They occasionally visualized subarachnoid blood up to nine days after the rupture. In 20 cases of aneurysms studied with CT scan and

TABLE 2

\begin{tabular}{|c|c|c|c|c|c|c|c|c|c|c|}
\hline \multirow{3}{*}{$\begin{array}{l}\text { Changes } \\
\text { MIDLINE SHIFT } \\
(>3 \mathrm{~mm})\end{array}$} & \multicolumn{2}{|c|}{ ANGIO } & \multicolumn{8}{|c|}{ CT PATHOLOGY } \\
\hline & \multirow{2}{*}{$\begin{array}{c}\text { No. Angios } \\
10\end{array}$} & \multirow{2}{*}{$\frac{\% \text { of Angios }}{16 \%}$} & \multicolumn{2}{|c|}{ ICH } & \multicolumn{2}{|c|}{ IVH } & \multicolumn{2}{|c|}{ OED } & \multicolumn{2}{|c|}{ Normal } \\
\hline & & & $\begin{array}{l}n \\
3\end{array}$ & $\begin{array}{l}\mathrm{R} \% \\
(30)\end{array}$ & $\begin{array}{l}n \\
2\end{array}$ & $\begin{array}{l}\mathrm{R} \% \\
\text { (20) }\end{array}$ & $\begin{array}{l}n \\
8\end{array}$ & $\begin{array}{l}\mathrm{R} \% \\
(80)\end{array}$ & $\begin{array}{l}n \\
1\end{array}$ & $\begin{array}{l}\mathrm{R} \% \\
(10)\end{array}$ \\
\hline NO MIDLINE SHIFT & 54 & $84 \%$ & 14 & (26) & 10 & (19) & 12 & (22) & 32 & (59) \\
\hline MCA AXIS DISPLACED & 11 & $17 \%$ & 3 & (27) & 2 & (18) & 8 & (73) & 4 & (36) \\
\hline MCA AXIS NORMAL & 53 & $83 \%$ & 14 & (26) & 10 & (19) & 12 & (23) & 29 & (55) \\
\hline
\end{tabular}

Comparison of space occupying lesions seen on the CT scan with evidence of space occupying lesion on angiograms for studies done within 2 days of one another ICH - intracerebral hematoma, IVH - intraventricular hematoma, OED oedema, $\mathrm{n}$ - number of scans, MCA - middle cerebral artery. 
TABLE 3

\begin{tabular}{|c|c|c|c|c|c|c|c|c|c|}
\hline \multirow[b]{2}{*}{ NO. CT SCANS } & \multirow{2}{*}{$\begin{array}{c}\text { SPASM } \\
\text { ON } \\
\text { ANGIOS }\end{array}$} & \multicolumn{8}{|c|}{ CT FINDINGS } \\
\hline & & SAH & ICH & IVH & OED & INF & $\mathrm{HC}$ & SD & NORMAL \\
\hline \multirow{2}{*}{$\begin{array}{l}\text { PRE-OP } \\
76(56 \%)\end{array}$} & $\begin{array}{l}\text { NO SPASM } \\
56(74 \%)\end{array}$ & $18(32 \%)$ & $14(25 \%)$ & $13(23 \%)$ & $11(20 \%)$ & $8(14 \%)$ & $29(52 \%)$ & $1(2 \%)$ & $11(20 \%)$ \\
\hline & $\begin{array}{l}\text { SPASM } \\
20(26 \%)\end{array}$ & $7(35 \%)$ & $6(30 \%)$ & $2(10 \%)$ & $4(20 \%)$ & $3(1.5 \%)$ & $13(65 \%)$ & $0(0 \%)$ & $1(5 \%)$ \\
\hline \multirow{2}{*}{$\begin{array}{l}\text { POS T-OP } \\
60(44 \%)\end{array}$} & $\begin{array}{c}\text { NO SPASM } \\
23(38 \%)\end{array}$ & $0(0 \%)$ & $1(4 \%)$ & $0(0 \%)$ & $6(26 \%)$ & $8(35 \%)$ & $10(44 \%)$ & $1(4 \%)$ & $2(9 \%)$ \\
\hline & $\begin{array}{l}\text { SPASM } \\
37(62 \%)\end{array}$ & $5(14 \%)$ & $4(11 \%)$ & $1(3 \%)$ & $22(60 \%)$ & $4(11 \%)$ & $22(60 \%)$ & $6(16 \%)$ & $1(3 \%)$ \\
\hline
\end{tabular}

INF - infarct, HC - hydrocephalus, SD - subdural

SAH - subarachnoid hemorrhage, ICH - intracerebral hematoma

IVH - intraventricular hematoma, OED - oedema

angiogram. Davis et al. (1976) observed that the CT scan provided improved visualization of intracerebral hematomas, intraventricular hemorrhage, infarction, subarachnoid hemorrhage and partial thrombosis of the aneurysm.

In a clinical pathologic study of 8 cases, Butzer et al. (1976) demonstrated an excellent correlation between CT scans and pathologically verified hematomas. They noted that the CT scan was superior to angiography in diagnosing hematomas. In 23 cases of intracerebral and/or intraventricular hematoma described by Scott et al. (1974) (none of which were due to ruptured aneurysm) CT scanning was superior to angiography. It provided considerable additional information on the localization and extent of the hematoma, associated edema and mass effect and intraventricular clot. Hayward and O'Reilly (1976) carried out retrospective analysis of 100 cerebral hematomas demonstrated by CT scan. Fifty-two of these patients had aneurysms, 38 had primary hematomas, 8 had angiomas and 2 had tumors. They made a retrospective diagnosis of primary intracerebral hematoma or aneurysm with 90 percent accuracy. They thought that a hematoma of the cavum of the septum pellucidum or the corpus callosum could be taken as an absolute sign of an anterior cerebral complex aneurysm. Their differential diagnostic accuracy fell to 66 percent for those hematomas associated with the internal carotid complex. In 38 intracerebral hematomas not due to aneurysms the locations were: external capsule in $12(32 \%)$, thalamus in $11(29 \%)$ and head of the caudate nucleus in $11(29 \%)$. We do not think the location of hematomas on the CT scan permits quite as high a degree of diagnostic accuracy prospectively, but this is not usually a problem when both angiographic and CT data are available.

The CT scan gives an accurate measurement of ventricular size. In a correlative study of Evans' index obtained by pneumogram and the ventricular brain ratio (VBR) obtained by CT scan, Synek et al. (1976) found an extremely good correlation (.95). Their estimation of VBR requires a planimeter. The ventriculocranial ratio used by us only requires a millimeter rule. $\mathrm{Hy}$ drocephalus in adults secondary to rupture of intracranial arterial aneurysms was studied using angiograms (Galera and Greitz, 1970). Their estimates of ventricular size were based on measurements of the distance between the internal cerebral vein and the lateral extension of the thalamo-striate vein. In 100 patients, who had subarachnoid bleeding as a consequence of ruptured aneurysm, 34 developed definite enlargement of the lateral ventricles. These 34 patients had slower circulation time and a higher incidence of arterial spasm. There was little difference related to the presence of
TABLE 4

\begin{tabular}{|l|c|c|}
\hline Time Post-SAH & $\begin{array}{c}\text { Ventriculo- } \\
\text { cranial } \\
\text { Ratio }\end{array}$ & $\mathbf{n}$ \\
\hline 1ST WEEK & .19 & 33 \\
\hline 2ND WEEK & .16 & 17 \\
\hline $2-6$ WEEKS & .21 & 37 \\
\hline$>6$ WEEKS & .25 & 30 \\
\hline NO SAH & 18 & 7 \\
\hline
\end{tabular}

$\mathrm{n}$ - number of CT scans

hematomas, aneurysm site, number of hemorrhages, intracranial operations, sex and age. In their series, hydrocephalus was manifest as early as three weeks after hemorrhage, but in most instances a progressive course of months or years occurred. Of the 34 with hydrocephalus 44 percent were asymptomatic. They noted that the clinical picture was not always proportional to the degree of dilatation. It was important that an unexpectedly poor clinical outcome in one out of five patients was due to post-hemorrhagic communicating hydrocephalus which was potentially treatable. Perhaps in this area CT scanning may make the greatest contribution to reducing morbidity.

Actual demonstration of aneurysms has already been shown. It seems that at least one dimension must exceed $29 \mathrm{~mm}$ (Press et al., 1975).

The results of this study are consistent with previous observations 
TABLE 5

\begin{tabular}{|c|c|c|c|c|c|c|c|c|c|c|c|c|c|c|c|c|}
\hline \multirow{2}{*}{$\begin{array}{r}\text { CT } \\
\text { PATHOLOGY }\end{array}$} & \multirow[b]{2}{*}{$\mathrm{n}$} & \multicolumn{15}{|c|}{ GRADE } \\
\hline & & \multicolumn{3}{|c|}{1} & \multicolumn{3}{|c|}{2} & \multicolumn{3}{|c|}{3} & \multicolumn{3}{|c|}{4} & \multicolumn{3}{|c|}{5} \\
\hline & & $\mathrm{n}$ & $\mathrm{r} \%$ & $\mathrm{c} \%$ & $\mathrm{n}$ & $\mathrm{r} \%$ & $\mathrm{c} \%$ & $\mathrm{n}$ & $\mathrm{r} \%$ & $\mathrm{c} \%$ & $\mathrm{n}$ & $\mathrm{r} \%$ & $\mathrm{c} \%$ & $\mathrm{n}$ & $\mathrm{r} \%$ & $\mathrm{c} \%$ \\
\hline SAH & 33 & 4 & 12 & 9 & 12 & 36 & 27 & 5 & 15 & 7 & 8 & 24 & 14 & 4 & 12 & 20 \\
\hline $\mathrm{ICH}$ & 28 & 3 & 11 & 7 & 5 & 18 & 11 & 9 & 32 & 12 & 8 & 29 & 14 & 3 & 11 & 15 \\
\hline IVH & 18 & 1 & 6 & 2 & 3 & 17 & 7 & 4 & 22 & 5 & 7 & 39 & 12 & 3 & 17 & 15 \\
\hline OED & 43 & 8 & 19 & 18 & 4 & 9 & 9 & 15 & 35 & 20 & 13 & 30 & 22 & 3 & 7 & 15 \\
\hline INF & 20 & 4 & 20 & 9 & 2 & 10 & 5 & 7 & 35 & 9 & 6 & 30 & 10 & 1 & 5 & 5 \\
\hline $\mathrm{HC}$ & 75 & 15 & 20 & 34 & 14 & 19 & 32 & 30 & 40 & 40 & 10 & 13 & 17 & 6 & 8 & 30 \\
\hline SD & 7 & 0 & 0 & 0 & 0 & 0 & 0 & 1 & 14 & 1 & 6 & 86 & 10 & 0 & 0 & 0 \\
\hline NORMAL & 17 & 9 & 53 & 21 & 4 & 24 & 9 & 4 & 24 & 5 & 0 & 0 & 0 & 0 & 0 & 0 \\
\hline $\mathrm{n}$ & 241 & 44 & & & 44 & & & 75 & & & 58 & & & 20 & & \\
\hline
\end{tabular}

Grade 1 - normal, Grade 2 - drowsy, headache and stiff neck, Grade 3 - major neurological deficit, Grade 4 - major neurological deficit, unconscious but still responsive to pain, Grade $5-$ moribund with failing vital signs. $n-$ number of CT scans.

SAH - subarachnoid hemorrhage, ICH - intracerebral hematoma, IVH - intraventricular hematoma, OED - oedema, INF — infarct, HC — hydrocephalus, SD - subdural

TABLE 6

\begin{tabular}{|c|c|c|c|c|c|c|c|c|c|c|c|c|}
\hline & & \multicolumn{5}{|c|}{ CT SCAN } & \multicolumn{2}{|c|}{ ANGIOGRAM } & \multicolumn{4}{|c|}{ CLINICAL FINDINGS } \\
\hline & No. & $\begin{array}{c}\text { PREOP } \\
\text { IVH }\end{array}$ & $\begin{array}{l}\text { PREOP } \\
\text { ICH }\end{array}$ & $\begin{array}{c}\text { PREOP } \\
\text { HC }\end{array}$ & $\underset{\text { INF }}{\text { POSTOP }}$ & $\begin{array}{c}\text { POSTOP } \\
\text { HC }\end{array}$ & $\begin{array}{c}\text { PREOP } \\
\text { SP }\end{array}$ & $\underset{\text { SP }}{\text { POSTOP }}$ & $\begin{array}{l}\text { AVE } \\
\text { BP }\end{array}$ & $\begin{array}{l}\text { AVE } \\
\text { Age }\end{array}$ & $\begin{array}{l}\text { Days to } \\
\text { Surg. } \\
\text { Post-SAH }\end{array}$ & Grade \\
\hline DEAD & 16 & $\begin{array}{l}7 / 16 \\
44 \%\end{array}$ & $\begin{array}{l}8 / 16 \\
50 \% \\
\end{array}$ & $\begin{array}{l}5 / 16 \\
31 \%\end{array}$ & $\begin{array}{c}5 / 8 \\
63 \%\end{array}$ & $\begin{array}{c}1 / 8 \\
13 \%\end{array}$ & $\begin{array}{l}3 / 15 \\
20 \%\end{array}$ & $\begin{array}{c}5 / 6 \\
83 \%\end{array}$ & 137 & 47 & 16 & 3 \\
\hline ALIVE & 40 & $\begin{array}{l}6 / 35 \\
17 \%\end{array}$ & $\begin{array}{l}9 / 35 \\
26 \%\end{array}$ & $\begin{array}{l}6 / 35 \\
17 \%\end{array}$ & $\begin{array}{r}12 / 28 \\
43 \%\end{array}$ & $\begin{array}{r}10 / 28 \\
36 \%\end{array}$ & $\begin{array}{l}6 / 40 \\
15 \%\end{array}$ & $\begin{array}{r}20 / 29 \\
69 \%\end{array}$ & 142 & 45 & 15 & 2 \\
\hline TOTAL & 56 & $\begin{array}{l}13 / 51 \\
26 \%\end{array}$ & $\begin{array}{l}17 / 51 \\
33 \%\end{array}$ & $\begin{array}{l}11 / 51 \\
22 \%\end{array}$ & $\begin{array}{c}17 / 36 \\
47 \%\end{array}$ & $\begin{array}{c}11 / 36 \\
31 \%\end{array}$ & $\begin{array}{l}9 / 55 \\
16 \%\end{array}$ & $\begin{array}{c}25 / 35 \\
71 \%\end{array}$ & 138 & 46 & 15 & 2 \\
\hline
\end{tabular}

Correlations with clinical outcome. PREOP - pre-operative, POSTOP - post-operative. AVE. BP — average systolic blood pressure on admission. The numbers in the columns for the CT scan and angiographic features refer to the patients. A patient was considered to have a particular feature such as a pre-operative intraventricular hemorrhage if any of the pre-operative studies showed this feature. Similarly for the post-operative columns.

on the primary importance of the patient's clinical status with respect to prognosis following rupture of intracranial aneurysms. Our improved ability to diagnose intracerebral and intraventricular hemorrhages may lead us to place more emphasis on these factors than angiographic spasm in the timing of surgery and management of such patients. CT scans will aid the decision to shunt patients, to evacuate hematomas and to appropriately treat postoperative complications such as edema and subdural collections. The CT scan may identify which aneurysm has ruptured in those patients with multiple aneurysms. 


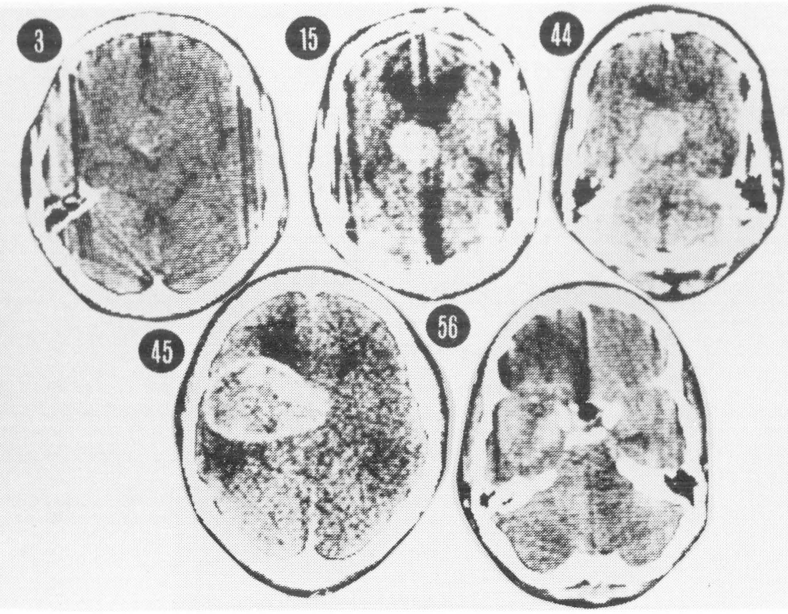

Figure la-CT scans on five patients in whom the aneurysm could be seen. Numbers refer to individual patients in series.

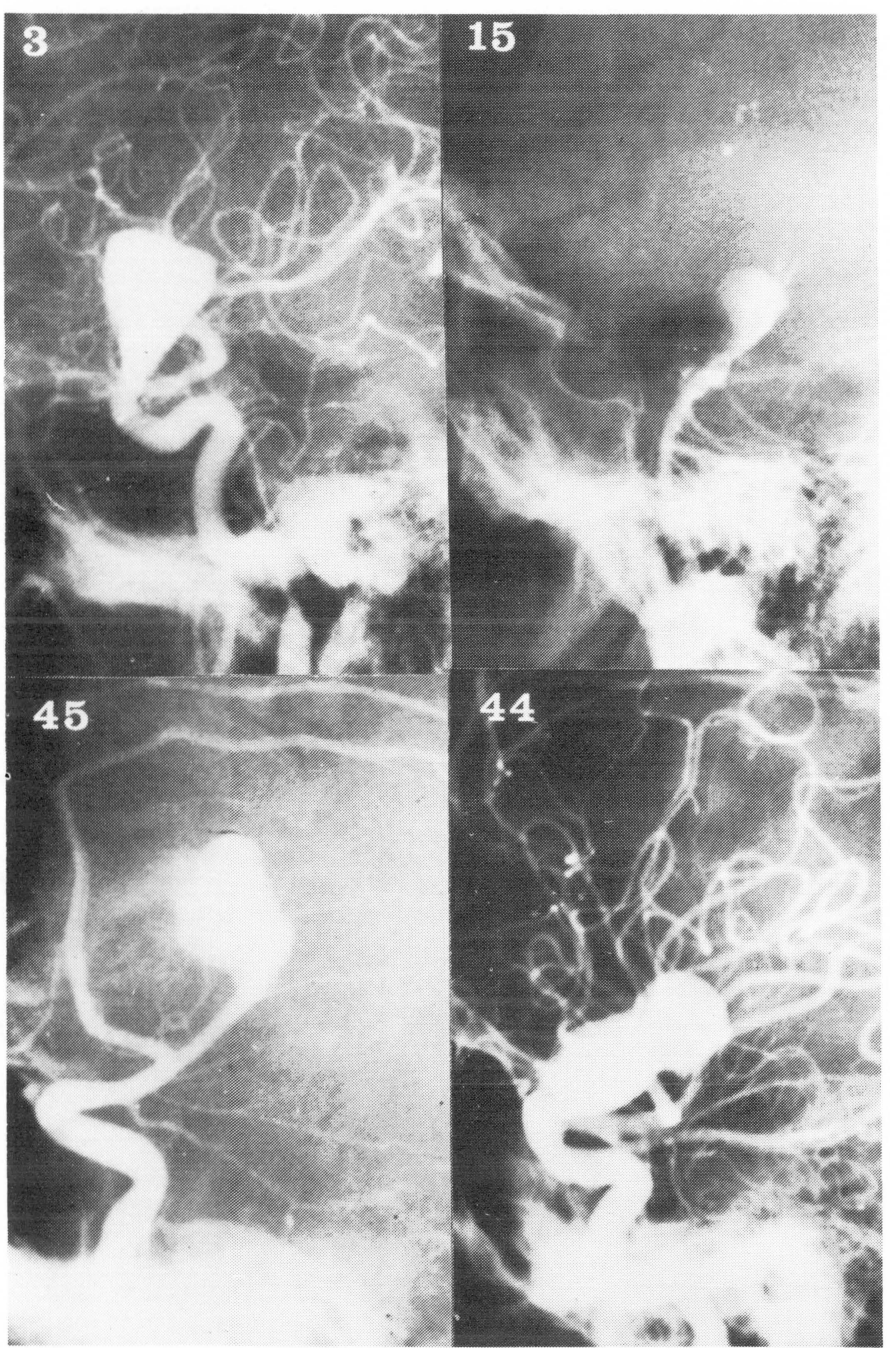

Figure $1 b$-Angiograms corresponding to the CT scans of Figure 1a. The angiogram on patient 56 showed no intracranial filling. Aneurysms occasionally appear larger on CT scans than by angiography, as with cases 15 and 45 .

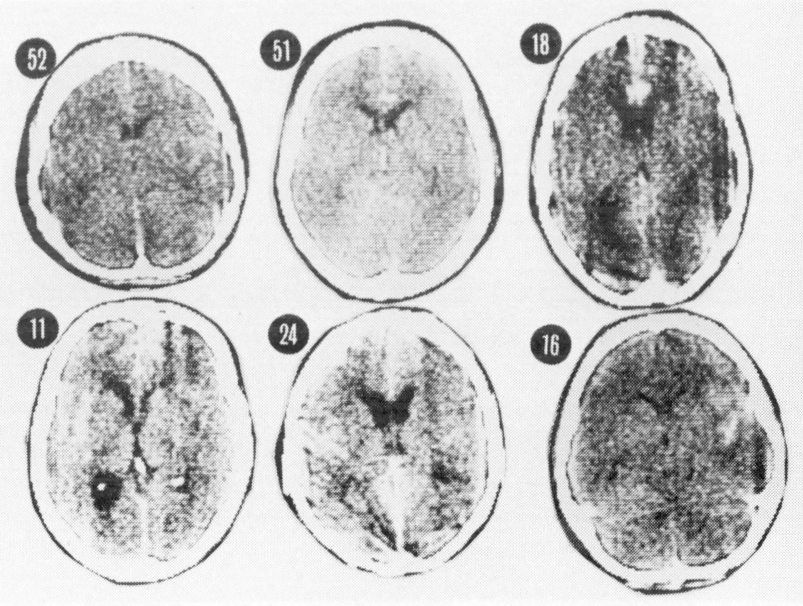

Figure 2-Six examples of subarachnoid hemorrhage.

Case 52, right middle cerebral aneurysm, 2 days post-SAH. Case 51, anterior communicating aneurysm, 19 days post$\mathrm{SAH}$. Case 18, anterior communicating aneurysm, 15 days post-SAH. Case 11, anterior communicating aneurysm, 7 days post-SAH. Case 24, basilar aneurysm, 2 days post$\mathrm{SAH}$. Case 16, right middle cerebral aneurysm, 3 days post-SAH. The interhemispheric subarachnoid spaces are distended with blood except in Case 16 where blood is seen in subarachnoid space of the Sylvian fissure on the right.

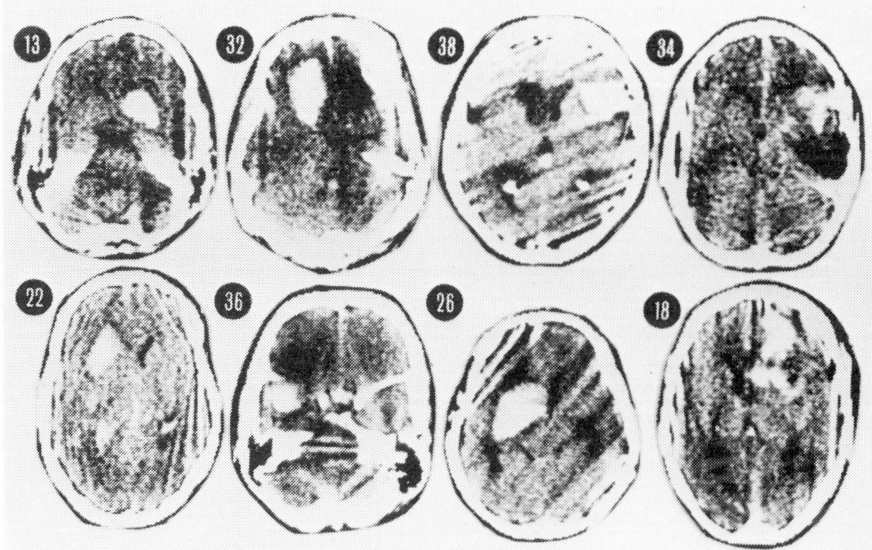

Figure 3-Eight cases with intracerebral hematomas.

Case 13, right middle cerebral aneurysm, 5 days post-SAH. Case 32, left middle cerebral aneurysm, 1 day post-SAH. Case 38, right middle cerebral aneurysm, 10 days post-SAH. Case 34, right internal carotid aneurysm, 2 days post-SAH. Case 22, left middle cerebral aneurysm, day of SAH. Case 36, left middle cerebral aneurysm, 13 days post-SAH. Case 26 , left internal carotid aneurysm, day of SAH. Case 18, anterior communicating aneurysm, 15 days post-SAH. The hematomas are generally homogeneous dense elliptical "snow-balls" with fairly smooth margins although more complex shapes can occur (cases 34 and 18). 


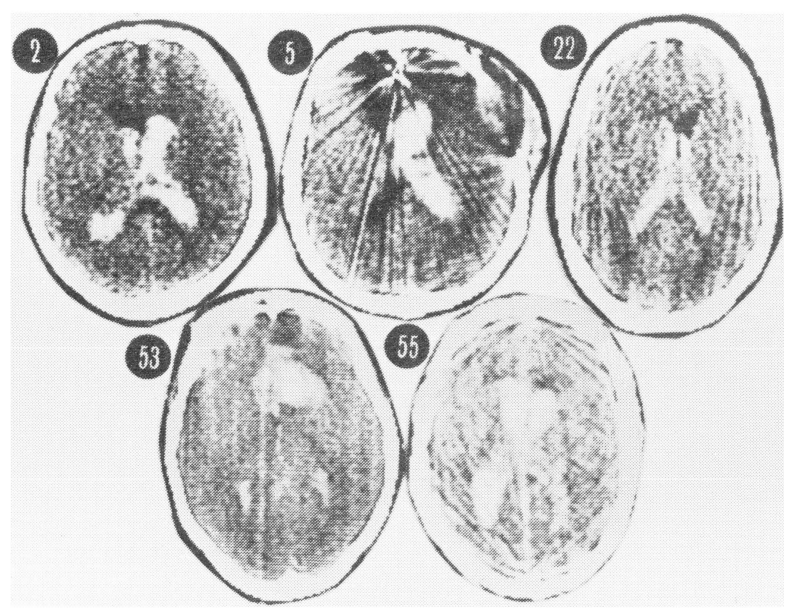

Figure 4-Five examples of intraventricular hemorrhage.

Case 2, right internal carotid aneurysm, 5 days post-SAH. Case 5, right internal carotid artery aneurysm, same day as $\mathrm{SAH}$. Operation done same day as SAH, post-operative CT scan. Case 22, left middle cerebral aneurysm, day of SAH. Case 53, anterior communicating aneurysm, 3 days post$\mathrm{SAH}$. Case 55, anterior communicating aneurysm, day of $\mathrm{SAH}$. Of these cases only No. 55 died. The blood generally makes a white cast of the ventricles, although it may settle in the more dependent occipital portions.

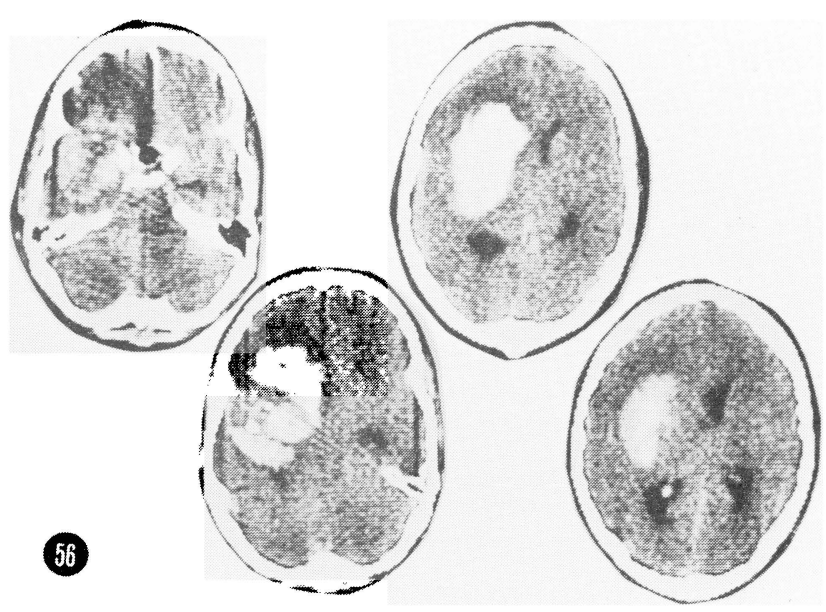

Figure 5-Four slices demonstrating a giant left middle cerebral aneurysm which has ruptured superiorly There was nonfilling on the angiogram. Patient died shortly after the CT scan was taken on day of SAH. The fresh hematoma superior to the actual giant aneurysm (top right) is more dense and homogeneous than the older laminated and partly calcified aneurysm (top left). A lucent halo of edematous brain surrounds the aneurysm and the clot.

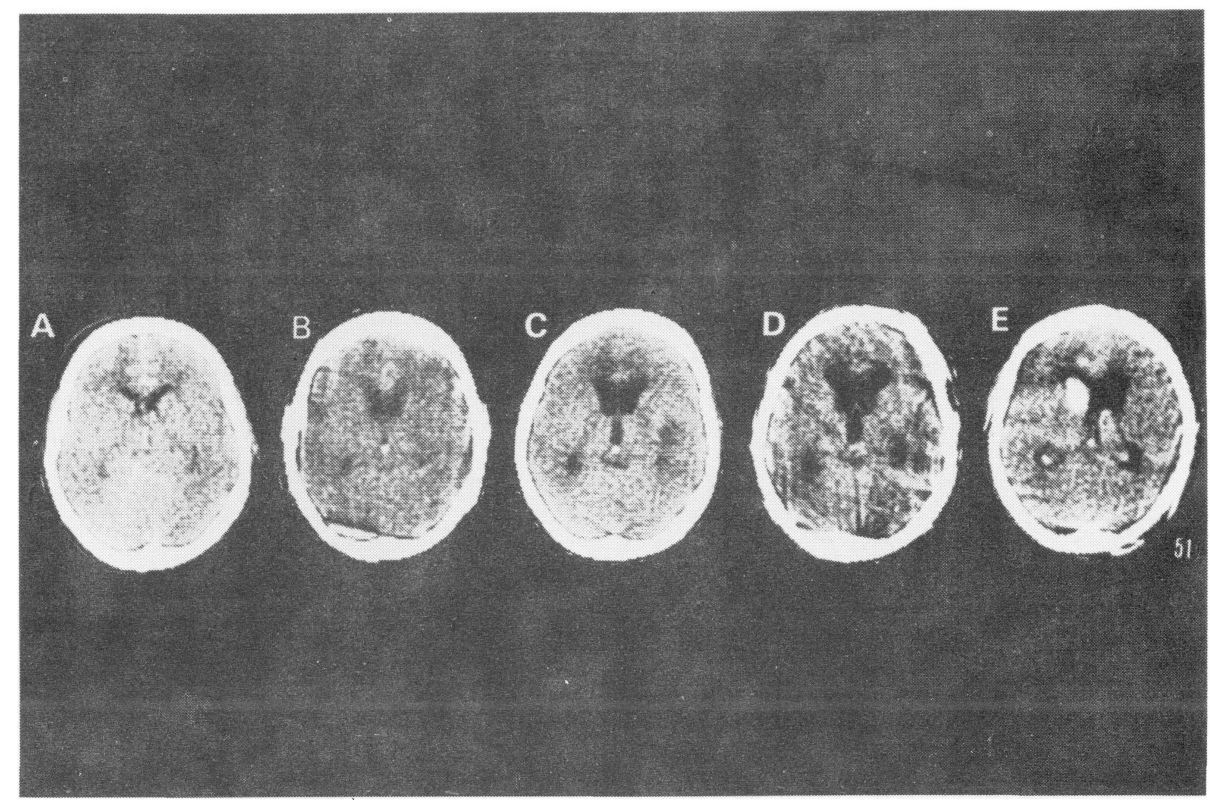

Figure 6-Case 58, anterior communicating aneurysm. a) 19 days post-SAH, b) 22 days post-SAH, c) 23 days post-SAH, d) 33 days post-SAH, e) 54 days post-SAH. The patient was neurological grade 4 from the outset and had a second major bleed on the 54th day prior to the last scan. 35 days separated the first and last scans. She was operated on the 64th day post-SAH and died post-operatively. 


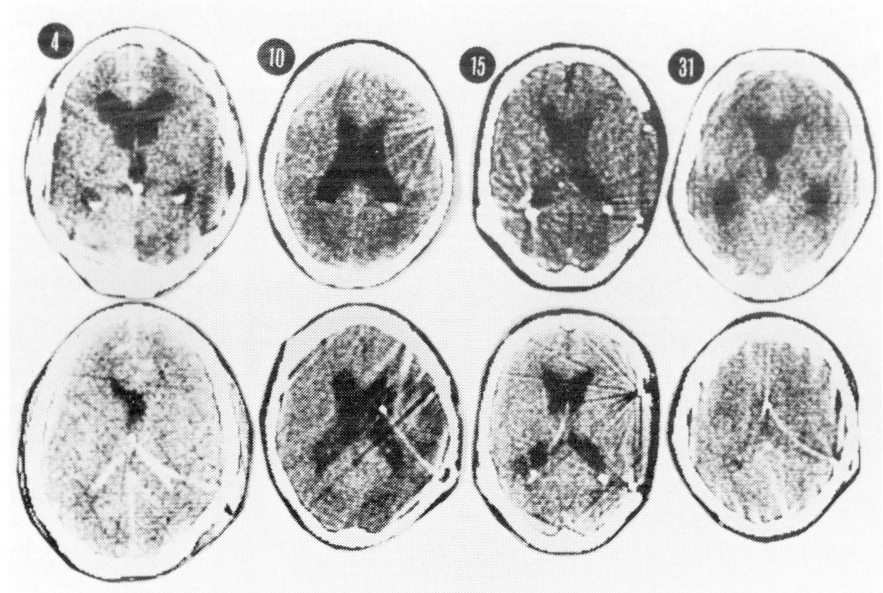

Figure 7-Top and bottom scans are from the same patient. Examples of CT scans before and following operative procedures.

Case 4. anterior communicating aneurysm, day of SAH, clinical grade 1 Post-shunt CT scan done on the post-SAH day 4 , the day of surgery There was an acute reduction in ventricular size with the shunt. The patient died on the fourth post-operative day, following a second SAH.

Casc 10, pre-shunt CT scan done 24th day post-SAH, 21 st post-clipping of aneurysm. Post-shunt scan done 82nd day post-SAH. There was a marked clinical improvement postshunting although not much reduction in ventricular size. Case 15, basilar aneurysm. Patient had shunt on second post-SAH day and clipping of aneurysm on 30th post-SAH day There was no change in ventricular size between the 7 th and 97 th post-SAH days (CT scans shown).

Case 31, basilar aneurysm, pre-shunt CT scan done on second day post-SAH. Post-shunt CT scan done on 9th post-SAH day There is a reduction in ventricular size, although the post-shunt scan cut is at a slightly higher level.

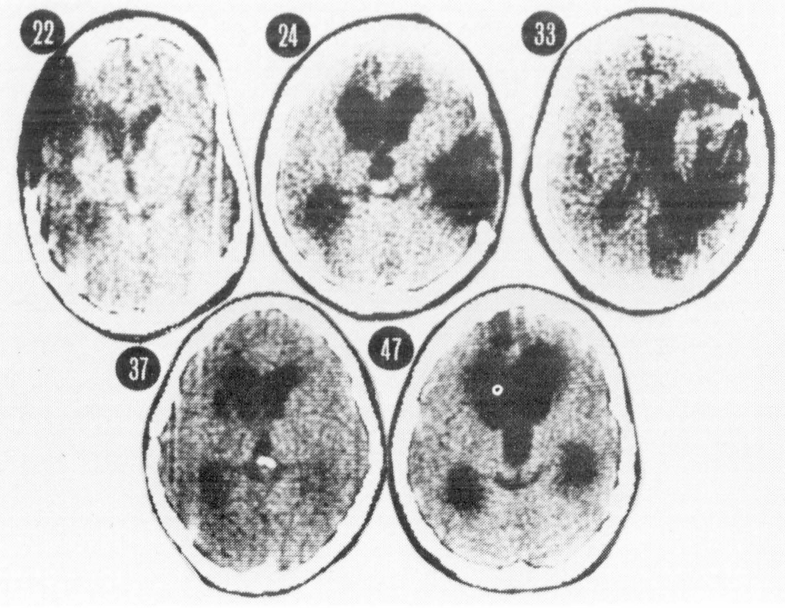

Figure 8-Five patients with cerebral infarction.

Case 22, left middle cerebral aneurysm. CT scan 32 nd day post-SAH, 30th day post-clipping. Clinical grade 3. Shift to the left.

Case 24, basilar aneurysm, 50th day post-SAH, 30th day post-operative clipping. Clinical grade 3. No shift.

Case 33, right middle cerebral aneurysm, 214th day postSAH, 213th day post-operative. Clinical grade 5. No shift. Case 37, left middle cerebral aneurysm, 152 days postoperative. Clinical grade 1 No shift.

Case 47 , anterior communicating aneurysm, post-SAH day 82. Clinical grade 4. Patient was subsequently shunted with improvement to grade 3 . No shift.

\section{REFERENCES}

BUTZER, J. F., CANCILla, P A., and CORNELL. S. H. (1976). Computerized Axial Tomography of Intracerebral Hematoma. Arch. Neurol. 33: 206-214.

DAVIS, K. R., NEW, $P$ F J, and OJEMANN, R. G. et al. (1976). Computed Tomographic Evaluation of Hemorrhage Secondary to Intracranial Aneurysm. Am J Roentgenol 127: 143-153.

GALERA, R., and GREITZ, T. (1970). Hydrocephalus in the Adult Secondary to the Rupture of Intracranial Arterial
Aneurysms. J Neurosurg 32: 634-641.

HAYWARD, R. D., and O'REILLY, G. V A. (1976). Intracerebral Haemorrhage. Accuracy of Computerized Transverse Axial Scanning in Predicting the Underlying Aetiology The Lancet 1: 1-4.

KENDALL, B. E., LEE, B. C. P., and CLAVERIA. E. (1976). Computerized Tomography and Angiography in Subarachnoid Haemorrhage. Brit J Radiol 49: 483-501.

SCOTT, W R., NEW, P F. J., and DAVIS, K. R. et al. (1974). Computerized Axial
Tomography of Intracerebral and Intraventricular Hemorrhage. Radiology 112: 73-80.

SYNEK, V, REUBEN, J R., and DuBOUlaY, G. H. (1976). Comparing Evans' Index and Computerized Axial Tomography in Assessing Relationship of Ventricular Size to Brain Size. Neurology 26: 231-233.

PRESS, B. D., GILBERT, G. E., and DAVIS, D. O. (1975). Computerized Transverse Tomography of Vascular Lesions of the Brain. Part II Aneurysms. Am J Roentgenol Radium Ther Nucl Med 124: 215-219 